\title{
Morphological Awareness in Reading and Writing: A Review of Related Literature
}

\author{
Anastasia Grammenou* \\ Msc Humman Communication Sciences Newcastle upon Tyne Alexandroupolis, Greece
}

DOI: $10.36348 / \mathrm{sb} .2020 . \mathrm{v} 06 \mathrm{i} 04.001$

| Received: 26.03.2020 | Accepted: 02.04.2020 | Published: 21.04.2020

*Corresponding author: Anastasia Grammenou

\section{Abstract}

The aim of the present essay is to present a literature review on the contribution of morphological awareness to reading and spelling ability of typically developing children and children with dyslexia. Inflectional morphological awareness is acquired early on children's oral language. During course of written language acquisition morphological awareness contributes to reading and spelling ability of normally developing children in combination to phonological awareness. Several issues such as course of acquisition of inflection and derivational morphology in oral and written language are well documented in English language and presented in this paper.

Keywords: morphological awareness, dyslexia, oral language, acquisition.

Copyright @ 2020: This is an open-access article distributed under the terms of the Creative Commons Attribution license which permits unrestricted use, distribution, and reproduction in any medium for non-commercial use (NonCommercial, or CC-BY-NC) provided the original author and source are credited.

\section{WORD AND MORPHEME}

The prerequisite that language (spoken and written) consists of words is taken for granted. At the age of three, children know that they speak with "words" and can distinguish when a word belongs to their mother tongue $[1,2]$.

Despite the early intuitive use of the word "word", the attempt to clarify its concept is limited by the different use of the term. Thus, if we look for the meaning of the word "discount" we will come across in two meanings - a reduction in price/to underestimate the significance of or give no credence to.

Essentially, these are two different representations of the same word [3]. In the present work the term "word" refers to the physical substance of the word in the written and spoken language which is the form of the word [4].

The smallest indivisible part of words that carries semantic content or performs a grammatical function is called "morpheme" and is the subject of the branch of linguistic science called morphology [5, 6]. The morphemes are divided into lexical and grammatical or functional [7]. The lexical morpheme implies the meaning of the word and remains largely stable in the different types of the word. Functional morphemes on the other hand are alternated in order to serve the syntactic function of a word and are distinguished into inflectional morphemes and derived morphemes. Inflectional morphemes indicate syntactic relationships, while derived morphemes are used to produce new words.

\section{Metalanguage up-to-date}

Metalinguistic awareness is defined as "the person's ability to reflect on the language and to manipulate the structural elements of speech using it as an object and not to use it simply as a medium of communication [8]". This ability involves focusing the speaker's attention on content or meaning in the form of linguistic expression [9]. (Phonological and pragmatic). Although there are variations, as there are many types of metalinguistic awareness (syntactic, phonological and pragmatic) [10], metalingistic awareness is systematically used around 7 or 8 year old children [11].

\section{Morphematic awareness and reading ability \\ Morphematic awareness is defined by Carlisle [12] as "the conscious awareness of the formal structure of the words in which children are focused on, as well as their ability to handle this structure (page 194"). In practice, this definition postulates a series of tests designed to describe the acquisition of this capacity.}


Bialystok and Ryan [13] proposed a two-dimensional meta-linguistic modeling of the tests used in the study of the aforementioned ability in reading and writing, which takes as a basis the analytical knowledge and cognitive control.

The scientific interest in studying the effect of morphological information on writing began with the increased role of inflectional morphemes and derived morphemes in oral language. Inflectional morphemes and derived morphemes are gradually being acquired in the oral language up to the age of four [14]. In the first words of the infants, the plural number stated in nouns is almost absent. During the second year, the use of a plural number is displayed, followed by a period of superficial use of the rule, in regular and even irregular nouns that require changes in the word stem e.g. mouse (mouse) $\rightarrow$ mice. In the third year, the inflected morpheme of past tence (-ed) is used in regular verbs. At the same time the- ing morpheme is used in the formulation of present perfect, not always accompanied by the mandatory auxiliary verb in the appropriate formula (be).

Productive morphology is more complex and is acquired until the early stages of adolescence, as derived words usually differ from the initial words to the phonological composition and the syntactical relationships they convey [15]. The relationship between morphological awareness and reading ability is complex, as Mahony [16] points out; the morphemes represent semantic and syntactical relationships. The ability to produce derived words from initial words in order to satisfy syntactic, grammatical and semantic context of incomplete sentences was used by Mahony [16] in a study of adolescent students. This study was extended in group's of $1^{\text {st }}$ and $2^{\text {nd }}$ grade primary school students [17] and $3^{\text {rd }}$ to $6^{\text {th }}$ grade primary school students in the USA [18]. In all cases the morphological awareness, as measured by the ability to form derived words, was positively related to text comprehension and had an independent contribution of $4 \%$ for the first graders of the elementary school, $5 \%$ for the students in the upper elementary classes and $11 \%$ for adolescents, when the influence of phonological awareness, vocabulary, and age were excluded.

The study of Sinson, Mahony and Mann [18] confirmed the effect of morphological awareness on the reading of words and pseudo-words beyond the early stage of learning reading and writing. Moreover, it was demonstrated the differentiated influence of the grammatical type of words, (verbs, adjectives and adverbs) and the type of presentation (written or spoken). When the test concerned fulfillment of orally presented sentences with the appropriate word, students demonstrated higher scores on adjectives than other grammatical words (verbs, adverbs). The reverse pattern was observed in task with pseudo-words.
Pseudo-adjectives were more difficult to be formulated orally than pseudo-verbs, pseudo-nouns and pseudoadjectives. When the material was presented in written form no differentiation was observed between different grammatical categories. The ability to distinguish words with the same roots is a task which requires analytical knowledge and a higher level of executive control, as students are asked to distinguish the root of words and compare them with their spelling and meaning. This ability is associated with word and pseudoword reading in third up to sixth grade students, at a rate of $4 \%$, above the effect of phonological awareness and age [19, 17].

In the same token, Roman, Kirby, Parilla, Wade-Wooley, and Deacon [20] investigated the factors influencing the reading of words and pseudowords. They used the classic sentence completion task with the appropriate derived words [12] and the production of words and pseudowords from initial words or pseudowords with same root [21]. Phonological awareness was measured by the initial phoneme deletion tas $\kappa$, spelling with orthographic acceptance test, and retrieving from the long-term memory with automatization naming task of letter and numbers. The results demonstrated that all variables contributed independently to reading with phonological awareness and morphological awareness to be in the first two positions, respectively, in reading words and pseudowords.

\section{Morphological awareness in written language}

The acquisition of literacy in shallow orthographic systems, as is the case of Greek, extends to a depth of at least four years, as determined by theoretical models developed in the light of constructivism [22-24] and of phonological processing theories [25-27].

According to the first theoretical frame, students adopt and reconstruct hypotheses regarding the written language until they reach the literacy principle that is to understand that letters represent phonemes [23]. Studies of Ferreiro and her colleague's postulates the existence of the pre-syllabic, the syllabic and the alphabetic stage. In the pre-syllabic stage, children quantify the words. In that respect words that refer to larger objects, occupy more space in writing [28], and at the same time they consist of "arrays" of different letters in a similar manner that words consist of different phonemes [24]. In the syllabic stage all syllables are represented by a letter that is always a vowel, as research has shown in Spanish [23], Portuguese [29] and Italian [30]. Further contact with written language leads the students to the conclusion that the number of letters exceeds the number of syllables, realizing thus the alphabetic principle, where usually a letter represents a phoneme. The aforementioned stages of literacy acquisition where 
conducted in Roman languages which are characterized by high-grapheme correspondences (transparent languages), the vowels are voiced, and the words consist of more than one syllable [31]. In Frith's [25] and Ehri's [26, 32, 27], theoretical frame, phonological processing plays a predominant role. The first literacy stage on Frith's account is the ideographic stage. Students experience words as ideograms, when reading and they reproduced them as images. Many times the change in the context in which the word occurs leads to its non-recognition, while anchorages are not felt. Ehri calls this stage non-alphabetical. The next stage, the alphabetic, is characterized by the acquisition in reading and writing of the letter-phonological correspondence, where one phoneme is represented by a letter, although errors are due to false phonological analysis (e.g. cribles instead of troubles [33]. Ehri, in the 1994 review, distinguishes this stage into an early alphabetic and mature alphabetic stage. In the early alphabetic stage words are represented by certain consonants. Criterion of its acquisition is the representation of the initial and final letters. The mature alphabetic stage is characterized by full representation of the phonemes by a letter (phonetic transcription). It follows the orthographic stage, characterized by the use of historical orthography on words and the representation of morphemes.

Treiman, Cassar and Zukowski [34] have challenged the view of successive stages and have shown that early knowledge of the morphological word analysis contributes to the spelling of homophones in flaps. In a longitudinal study, five-years-old students could graphically represent the / $\mathrm{t} / \mathrm{d} / \mathrm{d}$ / phonemes in derived words such as dirty, but not when it was at the end of the words, for example city. Similar were the observations of Treiman and Cassar [35] regarding the representation of the nasal consonants / $\mathrm{n} /$ and / $\mathrm{m} /$ in consonant clusters at the end of derived words and stem words (e.g. hummed versus wind). Success in representing controversial phonemes in words was attributed by Trieman and its colleagues in morphological awareness, but it is not the only explanation. As Kemp [36] points out, students are likely to use the phonological decomposition of the original word and write the derived words in a similar manner (eg dirt $\rightarrow$ dirty) without understanding the semantic association of words.

\section{Morphological awareness in inflectional morphology}

During the course of literacy acquisition inflectional verb and noun morphology have been well documented in English language. Representation of plural morphemes in nouns (-s) appears earlier than the present participle in verbs (-ing), or the (-ed) form denoting the past tense $[37,38]$. The case of the past tense was thoroughly studied by Beers and Beers [39] in a study of elementary students from the first to the sixth grade. The first attempts of writing the past tense morpheme (-ed) were a phonetic transcription which is pronounced in three different ways: a) as / $\mathrm{t} /$ as in the word walked, b) / id / as in the word painted or c) as / d / as in the word «called». During the 2nd and 3rd grades, the number of words spelled with the appropriate morpheme (-ed) increased, but spelling rules applied on converting initial verb in its inflected form, such as consonant reduplication in verb stems (e.g. drop $\rightarrow$ dropped), and absorption of the final - e ( e.g. make $\rightarrow$ made) were absent.

Walker and Hauerwas [40] in a comparative study of students from first to third grade described the use of the aforementioned spelling rules in two inflected morphemes that denote the present progressive tense (ing) and the simple past (-ed) past tense respectively. In order to accurately account for students' spelling skills, researchers used an evolutionary model to evaluate the spelling of inflected morphemes. Thus, a morpheme can be omitted in writing (step 1), imprinted as it sounds (eg, -id, -d, -ed) (step 2), or spelled correctly (step 3). In the first grade students declared the presence of both final morphemes in a large percentage $(89 \%$ for the -ed morpheme and $98 \%$ for the -ing morpheme.) The use of phonetic transcription varied for the two morphemes. The -ed morpheme was phonetically transcribed at $56 \%$ of the cases, whereas representation of the -ing morpheme was higher $96 \%$. A year later, all the phonemes in the two morphemes were depicted in the script, with the differentiation being manifested in the rate of use of the orthographic spelling rules. Reduplication of the final phoneme of verb stems and the cut-off of the final -e was applied in $72 \%$ of the cases, in the formation of the present progressive tense and $60 \%$ in the formation of the simple past tense. Comparison between the two averages remained statistically significant, and it was equalized only in third grade.

Formation of the simple past tense with the addition of the appropriate suffix requires not only the awareness of the spelling changes in the stem of the verb, but also the changes in its phonological structure. Barber [41] distinguishes two classes of verbs, those that form the simple past tense without changes in the phonological structure of the initial verb stem, called regular verbs and those subjected to phonological changes in the original verb stem, called irregular verbs. Some of the irregular verbs form the simple past tense in a way that it sounds like regular verbs (ending in phonemes $/ \mathrm{d} /$, /t/) e.g. the verb "deal" which forms the simple past tense as "dealt". Nunes, Bryant and Bindman [21] studied the acquisition of simple past formation in the two verb categories (regular and irregular verbs) using pseudowords. The pseudowords were presented in short paragraphs of three sentences. The first two contained pseudowords-verbs in the simple present and in the present progressive respectively, while in the third sentence the missing 
Anastasia Grammenou., Sch Bull, April., 2020; 6(4): 83-92

pseudoword -verb, in the simple past tense, was presented orally and students had to write it down. If the students perceived the change in the phonological structure of the pseudoword-verb they would have to write it phonologically, without the morpheme -ed, as it was an irregular pseudoword-verb. Otherwise, if students used the-ed morpheme, the pseudoword-verb would have been falsely characterized as regular pseudoword-verb. Researchers found that as early as the age of six students exhibited awareness of the regular pseudoword-verbs and gradually abandoned the phonological transcription, using the appropriate morpheme -ed in simple past formation. While the percentage of the inflected morpheme -ed in regular pseudoword-verbs increased gradually, however, the identification of irregular pseudoword-verbs, which ends in $(\mathrm{d})$, or $(\mathrm{t})$, was not possible before the age of nine or ten years. Until that time, phonological awareness, as measured by initial phoneme discrimination, had a significant effect on simple past formation of regular and irregular verbs. Nunes and her colleagues attributed this phenomenon to the sequential acquisition of the grapheme-phoneme correspondence at an early stage and the memorization of orthography conventions at a later stage.

A special case of inflected morpheme is the use of the apostrophe followed by the grapheme /-s/ to declare the genitive case in singular number in nouns in the English language. The genitive case in plural number is noted with the use of the apostrophe in regular nouns (e.g. the nominative case singular number of the noun «boy» is transformed as «boy's» in genitive case singular number and «boys'» in genitive case plural number. In the irregular nouns the genitive case in plural number is noted by the apostrophe followed by the grapheme /-s/ (e.g. the nominative case singular number of the noun «child» is transformed as «child's» in genitive case of singular number and as «children's» in genitive case of plural number.

Bryan Nunes and Bindiman [48] reported the progress of a group of children from the age of eight to ten years, in their ability to write correctly the general singular and the nominal and accusative plural cases. Students were presented with written sentences containing gaps, which corresponded to the nouns in the appropriate cases. They had to use a noun in nominative singular case to fulfill the sentences. Phonological awareness task (initial phoneme identification), syntactic awareness tasks (sentence assembly and sentence construction) as well as morphological awareness tasks were also administrated. The morphological awareness tasks regarded simple past formation of regular and irregular verbs when simple present and present progressive was given and vice versa. The third task regarded derivational noun morphology that is formation of nouns when verbs or adjective were given.
Students found it particularly difficult to form the genitive singular with the use of the apostrophe, as their performance reached $50 \%$ during the 19 months of the survey. Success rate of writing the nominal and causative cases in plural number, were also at the same level. The main mistakes were omission of the apostrophe in genitive singular and erroneous application of it in general and accusative plural cases.

Multiple regressions showed that beyond the age, I.Q and reading ability, children's performance on spelling genitive singular, as well as spelling of nominal and the accusative plural cases, was predicted by performance on morphological awareness tasks, but not by syntactic or phonological awareness tasks. Moreover, derivational noun morphology that is noun production from verbs or adjectives, but not verb transformation, predicted the correct use of the apostrophe.

\section{Morphological awareness in derivational morphology}

Derivational morphology refers to subjects' ability to produce words from others according to phonological, orthographic and grammatical rules. Research reported below demonstrate that derivation of words is based on the knowledge of the spelling the initial word (stem or stem +suffixes) and is acquired by children at early ages.

Carlisle [42] was among the firsts to systematically study spelling ability of derived words according to orthographic and phonological changes in the structure of word stems, in students attending fourth, sixth and eighth grade. Words used in her research material were derived words originating from the initial ones by adding morphemes that (a) do not bring any change in the stem of the initial word b) bring a phonological change to word stem, c) bring a spelling change to word stems, and d) bring a phonological and spelling change to word stems. Students presented a higher percentage of errors in words that required phonological change and in words with a combination of phonological and spelling changes. In the reverse process, writing initial words from derivatives, students encountered more difficulty in words that required a combined change in spelling and phonology. Words that did not require any change presented the smallest error rate, while words with phonological change or spelling change were in the middle positions.

In the same research, Carlisle [42] administered an oral morphological awareness test, sentence completion with derived words when initial words given and vice versa, in accordance to spelling task. In oral morphological awareness test performance of the students was significantly better than spelling test of the initial and derived words confirming the hypothesis that the grammatical phenomena are 
acquired firstly in oral and then in the written language. Errors in derivational morphology were a) children's inability to formulate any word or pseudoword from the word given $b$ ) formulation of $a$ pseudoword with grammatical suffix, c) formulation of other word with the same stem as the initial word d) formulation of pseudoword with stem and suffixes that do not exist in English language (ungrammatical pseudowords).

Rate of children's inability to produce words or pseudowords and rate of ungrammatical pseudoword production gradually decreased in the three groups of students. Pseudowords productions with grammatical suffixes are found in derivation process of initial words that require phonological changes. These errors relate to the production of words that undergo phonological change during the production process, and consist of $17 \%$ of all errors. The anticipated correct derived words were replaced by pseudowords that preserved the phonological structure of the initial words adding one of the following suffixes:-ment, ance, -tion, ness, -less. Unfortunately, Carlisle [42] does not report the rate of use of these suffixes in all English language entries. Production of a correct derived word with the same stem as the initial word was observed at $80 \%$ of specific cases whose initial words were the words warm, deep, equals, consume, and heal.

Early acquisition of noun inflection versus verb or adverb inflections was confirmed by Kemp, Nilsson and Arciuli [43]. They used three tests, sentence completion with a pseudoword, grammatical judgment of sentences containing a pseudoword and grammatical categorization of words and pseudowords. Students attending first year at college demonstrated higher rates in pseudowords with noun suffixes, followed by pseudowords with verbs and adverb suffixes.

In French Language, Senechal [18] showed that pupils in second grade evaluated spelling of words that contained voiceless consonants at word ends using morphological relationships. In some words, the existence of the voiceless consonant can be predicted by another derived word, e.g. in the word "grand" (grand), students can denote the consonant if they associate it with the corresponding noun in which all graphemes are pronounced e.g. "grande" (large). However, there are also words in which the voiceless consonants are not indicated by grammatical-morphological relationships, and students have to memorize the writing of these words. Success rate in writing consonant words is low. In the same study, the effect of the grammatical gender one recording voiceless consonant was observed. Words that had the same root as female nouns had substantially higher success rates than other words which were morphologically related words belonged to a different grammatical category or even to a different gender.

In a later study, Sénéchal, Basque and Leclaire [44] used a protocol to record the strategies used by students to write words with voiles consonants. The most commonly used strategies were recall from memory of the spelling that researchers coded as "a mnemonic technique", its semantic correlation with others sharing the same stem, which was coded as "a morphological correlation", and matching of phonemes with letters coded as "a phonological strategy"|.

The most successful technique was memory recall, which was successful in all three categories of words used and was (a) words without a voiceless consonant, (b) words with a morphological correlation, and (c) non-morphologically consistent words. The morphological correlation was used equally with the mnemonic technique in morphologically related words and had an equally high success rate.

\section{Morphological awareness in children with dyslexia}

Student's with dyslexia production and understanding of spoken language and use of the morphological level of language, was studied in the light of two theoretical approaches, the Structural Lag Hypothesis and the Processing Limitation Hypothesis). Supporters of the first view believe that linguistic structures, grammatical morphemes used in inflectional noun and verb morphology, derivation suffixes and subordinate clauses appear late in the oral speech of children with dyslexia and are therefore not fully understood [45-47]. Supporters of the second view believe that dyslexic individuals differ from normal readers in phonological function. According to this view, linguistic levels such as phonology, syntax, and semantics act autonomously, with defined principles and construct the Language Apparatus [48], but limitations on access to different language level information result in children's with dyslexia difficulties in language comprehension and production $[49,50]$. The methodological approach developed by researchers in describing the language skills of children with dyslexia was comparing them both with typically developing children and children with Specific Language Impairment, a syndrome characterized by difficulty in understanding and producing oral language, despite normal intelligence, the absence of sensory dysfunctions, emotional disturbance and cultural deprivation [51].

Lowest percentage of students with dyslexia and S.L.I., (19\%), was reported by Morris, Saywitz, Shankweiler, Katz, Stuebing, Fletcher, Lyon and Francis study [52]; the highest rates were recorded by Denkla and Mattis [53], 63\% and 60\%, respectively. Of particular interest is the case of students with S.L.I. who also have dyslexia during the first school years. 
Anastasia Grammenou., Sch Bull, April., 2020; 6(4): 83-92

Percentages ranged from $40 \%$ and $50 \%$ in researches by Catts [54] and Morris et al. [52], to $85 \%$ in the research by Neville, Coffey, Holcomb and Tallal [55]. McArthour and his colleagues [56] assessed at the same time 110 students who were diagnosed with dyslexia and 102 students diagnosed with S.L.I. to investigate the possibility of co-occurrence of the two syndromes. Rates of co-occurrence of the two syndromes were 55\% of dyslexic students who also showed S.L.I. and $51 \%$ of pupils with S.L.I who also met the dyslexia. Whether a student will be named as students with S.L.I., or dyslexia or as a student with both syndromes depends on the growing environment and the early diagnosis.

Genome mapping and the discovery of genes responsible for dyslexia led to the description and monitoring of individuals at risk for dyslexia [57, 58]. These children come from parents with a history of dyslexia and were assessed from their early age or from their birth, in a number of areas such as language development, visual-motor coordination and phonological awareness. The first findings of any deviations in language acquisition $t$ of infants at risk for dyslexia come from Snowling, Gallegher and Frith [59], who attended 56 infants from the age of 3 years and 9 months to 8 years. $66 \%$ of students at risk were identified as "children with dyslexia" at the age of 8 and had a low performance in all language tests at the age of 3 and 9 months and at the age of 6 when reassessed. On the other hand, students who were at risk and did not met the dyslexia criteria, had language development profiles similar to those of typically developing children, although their performance in phonological awareness and pseudoword decoding was lower than expected given their age.

More information on the role of morphological awareness in the oral language of children with dyslexia comes from research in languages with rich morphology such as Finnish, Dutch and Italian. Finnish language is characterized by the obligatory use of inflection morphemes for nouns, but also by the addition of grammatical morphemes marking preposition and pronouns. The Academy of Finland in collaboration with academics and researchers conducted the first longitudinal study of dyslexia, known as the Jyväskylä Longitudinal Study (JLS) of Dyslexia (20002005), which recorded the developmental history of children at risk for dyslexia (high risk children) and children who did not have this agent, from birth until the age of five. Researchers administered tests of assessment of speech, psychomotor development, perception of auditory stimuli, auditory memory, as well as evaluation of brain function with electroencephalograms (Event Related Brain Potentials). This review will list the findings related to the two groups' developmental language profiles.
In the first announcement of the JLS project [60] noted significant differences in the production and comprehension of language of the high-risk group children versus control group's speech from the age of two weeks to three and a half years. The areas of linguistic development that differentiated the two groups were the production of canonical babbling at about six weeks of age, the combination of two syllables representing different morphemes at the age of 38 weeks and production of phoneme series that resemble words at the age of 40 weeks. Difficulties in producing and understanding the high-risk group's spoken language continued to exist for up to three and a half years. At the same time, a percentage of children in the control group who had been delayed in gaining critical stages in language development had bridged the gap compared to their counterparts.

Use of the inflectional morphology, in nouns and verbs, in spontaneous and evoked infant speech, of the two groups of children involved in the JLS project, was reported three years later [61]. At the age of two years, morphosyntactic awareness was assessed by the following tests: a) the Mac Athur Development Inventory Parental Reference Scale [62], which assessed language development according to the information provided by parents, trained in recording grammatical morphemes of nouns and verbs; b) the spontaneous speech of children in a series of observations during play with familiar persons; c) the Bayley Scales of Infant Development -II [63], which evaluated verb and noun naming ability.

Language comprehension was assessed at 2.5 years of age using the Reynell Developmental Language Scale [64], while at 3.5 years the Dutch version of the Berko test was administered [60]. The later test assessed the ability to form the three degrees in adjectives, the noun inflections in singular and plural number, as well as verb transformations in correct persons. In addition, at the age of 5.5 years the following tests were administrated: a) the Inflection Morphology Test b) the Boston Naming Test and c) the Peabody Picture Vocabulary Test -Revised [65]. Two groups were differentiated from the age of 2 years on the Mean Length of Utterances with the high-risk group delivering a significantly smaller number of morphemes in its sentences (4.30 in the nouns and 3.87 in verbs, versus 5.09 and 4.34 of the control group, respectively). The trend became statistically significant at 3.5 years of age, with the high-risk group averaging 6.02 inflectional noun morphemes, 9.84 inflectional verb morphemes and 3.32 inflectional adjective morphemes versus $7.41,12.00$ and 4.25 for the control group, respectively. One and a half years later, the high-risk group had covered the difference to the control group in producing inflectional noun morphemes (9.64 versus 10.27 respectively), but was lagging behind in inflectional adjective morphemes (20.34 and 25.25 
respectively) and in inflectional verb morphemes (18.26 versus 20.28).

Carlisle [42] was the first to investigate the way in which children with dyslexia write derivative words resulting from monomorphematic ones, in accordance to English derivational morphology rules. In her research, she compared the performance of students with dyslexia in third grade junior high school with typically developing students in second grade junior high school, sixth and fourth grades of elementary school. In her study she used a series of tests assessing (a) the ability to generate derived words from initial ones to fit the meaning of sentences presented orally, e.g. warm, "He chosen the jacket for its (warmth)" and vice versa, that is, production of the initial word from derived word. e.g. Growth, "She wanted the plant to grow" b) writing of derivative words from initials that are presented in written language accompanied by sentences that match the requested word and vice versa (this task was similar to previously described task, but it presented in written language). c) Written production of pseudowords from initials presented in written language together with the suffixes to be used in production. Initial pseudowords were produced by words after changing a consonant or a consonant clusters. The overall picture of children's with dyslexia performance is similar to that of typically developing children. They appear to be lagging behind in the acquisition of derivational morphology skills, both in oral language, where dyslexics have developed the ability to form derivative words at the same level as that of one year younger typically developing students, as well as in written language.

Performance of children with dyslexia in derivational morphology in written language lagged behind five years, it was found to be at the same level as fourth grade students. At a similar level was performance of children with dyslexia in written derivational morphology, when the initial stem and the suffix were given. It seems that factors affecting performance of students with dyslexic in derivational morphology are present beyond the semantic and syntactic level, as dyslexic students are unable to benefit from semantic and syntactic functions.

Tsesmeli and Seymour [66] investigated the factors influencing children's with dyslexia performance in derivational morphology using two word categories. The first category consisted of frequently used initial and derivative words of the English language, while the second category consisted of words with Greek roots. Students with dyslexia scored lower on writing the two word categories than their peers, but at the same level as younger students who had the same reading age. The likelihood of correctly spelling one of the two words (initial or derivative) of a couple was higher in children with dyslexia $(43.95 \%$ for the first category and $60 \%$ for the second), versus $5 \%$ and $26.92 \%$ for the words of the first category in the two control groups, respectively, and $12.44 \%$ and $29.92 \%$ for the two control groups in the words of the second category. In addition, the types of errors that predominated in dyslexics were combined errors in stem and in suffixes $(44.79 \%$ and $44.37 \%$ respectively for the first and second word categories). Comparison of children with dyslexia to younger students of the same reading age in two oral tasks that assessed derivative word formation from initial and vice versa according to Carlisle's [42] model (trials a and c) showed that the two groups did not differ significantly.

Hauerwas and Walker [40] attempted to describe the way children with dyslexia write the inflected morphemes of present progressive tense, simple past tense and third person singular number of simple present, by introducing a new approach. They compared children with dyslexia with chronological age control group and students with the same spelling age. Their research material included a) completing sentences with the appropriate verbal form when the infinitive was given, which was either a pseudoword (oral test) or a regular word (written test) b) the writing of specific verbal forms when the infinitive was given and vise versa, c) spelling checking of pseudowordverbs derived from the composition of a stem and a verb inflection. Dyslexic students showed significantly higher rates of omission of the final -e, which characterize verbal formations. In addition, dyslexic individuals had a greater inconsistency in the spelling of the stem in their initial and derivative words $65.7 \%$ versus $80.7 \%$ of students with the same spelling ability and $98.9 \%$ of the age control group. Hierarchical regression analyses on the dyslexic group and students with the same spelling ability, on the ability to write the inflectional morphemes showed a different picture of the way the two groups approach this test.

Thus, in children with dyslexia writing of verbs could be explained by the ability to write the stem of verbs (a variable related to general spelling) by $54.6 \%$ and $7 \%$ by morphological awareness (as measured by oral completion of sentences with pseudoword-verbs in the corresponding form). In spelling age control group, spelling ability of verb inflections were explained by $49.5 \%$ from correct spelling of verb stems and $6 \%$ by general spelling ability as measured by the $\mathrm{c}$ test.

This finding led the researchers to conclude that children with dyslexia would benefit from developing the spelling ability of verbal endings by using a program aimed at developing morphological awareness.

Finally, Bourassa and Treiman [67] used the term 'morphemetic consistency' to describe children's 
ability to retain the initial word stem in derivatives. Two cases were distinguished; the first concerns derivative words, where the production process presupposes a change in phonology, but not in the spelling of the character of the subject, e.g. discuss $\rightarrow$ discussion and the second refers to changing the subject matter of words according to the phonology of the derivative word, e.g. explain $\rightarrow$ explanation. Two groups did not differ in stem retention in derived words, with the two groups having a higher success rate in writing derived words that did not require a spelling change, than the derived words with a dual change in phonology and spelling of the stem. In addition, the two groups showed the same percentage of consistency in writing the original and derivative words, which contradicts the earlier findings of Carlisle [42] and Tsesmeli and Seymour [66].

\section{SUGGESTIONS}

In English language, the acquisition of morphological awareness has been well documented in relation to noun and verb morphology. The literature review clearly demonstrated that morphological awareness and phonological awareness contribute to typically developing children's and children's with dyslexia reading and spelling ability. However, there are no comparative studies of children with dyslexia and typically developing children regarding the joint contribution (if any) of morphological awareness, phonological awareness and working memory to children's spelling ability in Greek Language.

\section{REFERENCES}

1. Messer, S. (1967). Implicit Phonology in Children. Journal of Verbal Learning and Verbal Behavior, 6, 609-613.

2. Cole, R. A. (1981). Perception of fluent speech by children and adults. Annals of the New York Academy of Sciences, 379(1), 92-109.

3. Di Sciullo, A.M., \& Williams, E. (1987). On defining the word. Cambridge: MIT Press.

4. Katamba, F. (1993). Morphology. New York: Psychology Press.

5. Harris, Z.S. (1951). Methods in Structural Linguistics. Chicago: University of Chicago Press.

6. Chomsky, N. (1986). Knowledge of Language: Its nature Origins and Use. New York: Harper and Row.

7. Petrounias, E. (1993). Modern Greek Grammar and cooperative analysis, Athens, University St Book.

8. Edwards, T.S., \& Kirkpatrick A.G. (1999). Metalinguistic Awareness in Children: A Developmental Progression, Journal of Psycholinguistic Research, 28(4), 313-329.

9. Owens, R.E.JR. (1996). Language Development, 4rth edition, Boston: Allyn and Bacon.

10. Fox, B., \& Ruth, D. (1976). Analyzing Spoken Language into Words, Syllables and Phonemes. A developmental Study. Journal of Psycholinguistic Research, 4, 331-342.

11. Saywitz, K., Cherry, Wilikinson, L. (1982). Age related differences in metallinguistic awareness. In S., Kuczai( eds). Language Development, (2). Language Thought and Culture. Boston: Hillsdale, NJ.

12. Carlisle, J. F., \& Feldman, L. B. (1995). Morphological awareness and early reading achievement. Morphological aspects of language processing, 189209.

13. Bialystok, E., \& Ryan, E.B. (1985). Toward a Definition of Metalinguistic Skill. Merrill-Palmer Quarterly, 31(3), 229-251.

14. Berko, J. (1958). The child's learning of English morphology, Word, 14, 150-177.

15. Nagy, W. E., Diakidoy, I. A. N., \& Anderson, R. C. (1993). The acquisition of morphology: Learning the contribution of suffixes to the meanings of derivatives. Journal of reading Behavior, 25(2), 155-170.

16. Mahony, D. (1994). Using sensitivity to word structure to explain variance in high school and college level reading ability. Reading and Writing: An Interdisciplinary Journal, 6, 19-44.

17. Mahony, D., Singson, M., \& Mann, V. (2000). Reading ability and sensitivity to morphological relations. Reading and Writing: $A n$ Interdisciplinary Journal 12(3), 191-218.

18. Singson, M., Mahony, D., \& Mann, V. (2000). The relation between reading ability and morphological skills: Evidence from derivational suffixes. Reading and writing: An Interdisciplinary Journal, 12, 219-252.

19. Carlisle, J. F., \& Nomanbhoy D. M. (1993). Phonological and Morphological Awareness in First-Graders, Applied Psycholinguistics, 14(1) 7795.

20. Roman, A. A., Kirby, J. R., Parrila, R. K., WadeWoolley, L., \& Deacon, S. H. (2009). Toward a comprehensive view of the skills involved in word reading in Grades 4, 6, and 8. Journal of Experimental Child Psychology, 102(1), 96-113.

21. Nunes, T., Bryant, P., \& Bidman, M. (1997a). Learning to spell regular and irregular verbs, Reading and writting: An interdisciplinary Journal, 9, 427-449.

22. Ferreiro, E. (1990). Literacy development: psychogenesis. How children construct literacy: Piagetian perspectives, 12-25.

23. Ferreiro, E., \& Teberosky, A. (1982). Literacy before schooling. New York: Heinemann.

24. Ferreiro, E., Pontecorvo, C., \& Zucchermaglio, C. (1996). Pizza or Piza? How children interpret the doubling of letters in writing.

25. Frith, U. (1985). Beneath the surface of developmental dyslexia. Surface dyslexia,32(1), 301-330. 
26. Ehri, L. C. (1991). The development of reading and spelling in children: An overview. Dyslexia: Integrating theory and practice, 63-94.

27. Ehri, L. C. (1998). Grapheme-phonerne knowledge is essential for learning to read words in English. Word recognition in beginning literacy, 3, 40.

28. Stella, G., \& Biancardi, A. (1990). Accesso alla lingua scritta e sistema verbale: Una integrazione complessa. [Oral language and the beginning of writing: A complex integration] Età Evolutiva, 35, $38-49$.

29. Nunes, T., Carraher, T., \& Rego, L. L. B. (1982). Understanding the alphabetic system. The acquisition of symbolic skills. New York: Plenum.

30. Pontecorvo, C., Orsolini, M., Burge, B., \& Resnick, L. B. (2014). Children's early text construction. Routledge.

31. Pollo, T. C., Treiman, R., \& Kessler, B. (2007). Three perspectives on spelling development. In Single-Word Reading (pp. 187-201). Psychology Press.

32. Ehri, L. C. (1994). Development of the ability to read words: Update.

33. Beech, J.R. (2005). Ehri's model of phases of learning to read: a brief critique. Journal of Research in Reading, 28, (1), 50-58.

34. Treiman, R., Cassar, M., Zukowski, A. (1994).What type of linguistic information do children use in spelling? The case of Flaps. Child Development, 65, 1310-1329.

35. Treiman R., \& Cassar, M. (1996). Effects of Morphology on Children's Spelling of Final Consonant Clusters. Journal of Experimental Child Psychology, 63, 141-170.

36. Kemp, N. (2006). 'Children's spelling of base, inflected, and derived words: Links with morphological awareness', Reading and Writing: An Interdisciplinary Journal, 19, 737-765.

37. Treiman, R. (1993). Beginning to spell: A study of first-grade children. New York: Oxford University Press.

38. Varnhagen, C., McCallum, M., Burstow, M.(1997). Is children's' spelling naturally stage-like? Reading and Writing: An Interdisciplinary Journal, 9, 451481.

39. Beers, C.S., Beers, J.W. (1992). Children's Spelling of English Inflection morphology. In Templeton,S., and Bear D.R. (eds) Development of orthographic knowledge and the foundation of literacy: A memorial festschrift for Edmund $H$. Henderson (231-252). Hillsdale, N.J., Lawrence Erlbaum.

40. Walker, J., Hauerwas., L.B. (2006). Development of Phonological, morphological, and orthographic knowledge in young spellers: The case of inflected verbs. Reading and Writing: An Interdisciplinary Journal, 19, 819-843.
41. Barber, C.(1993). The English Language: A Historical Introduction. Cambridge: Cambridge University Press.

42. Carlisle, J.(1988). Knowledge of Derivation Morphology and Spelling Ability in Fourth, Six, and Eight Graders. Applied Psycholinguistics, 9, 247-266.

43. Kemp, N., Nilsson, J., \& Arciuli, J., (2009). 'Noun or verb? Adult readers' sensitivity to spelling cues to grammatical category in word endings.' Reading and Writing: An Interdisciplinary Journal, 22, 661685.

44. Sénéchal, M., Basque, M. T., \& Leclaire, T. (2006). Morphological knowledge as revealed in children's spelling accuracy and reports of spelling strategies. Journal of Experimental Child Psychology, 95(4), 231-254.

45. Byrne, B., Fielding-Barnsley, R.(1991). Evaluation of a Program to Teach Phonemic Awareness to Young Children. Journal of Educational Psychology, 83(3), 451-455.

46. Byrne, B., Fielding-Barnsley, R.(1993). Evaluation of a Program to Teach Phonemic Awareness to Young Children.: A 1-year Follow-up. Journal of Educational Psychology, 85(1), 104-111.

47. Byrne, B., Fielding-Barnsley, R.(1995). Evaluation of a Program to Teach Phonemic Awareness to Young Children.: A 2-and 3-year Follow-up and a new Preschool Trial. Journal of Educational Psychology, 87(3), 488-503.

48. Fodor, J. A. (1983). The modularity of mind. MIT press.

49. Crain, S., \& Shankweiler, D. (1990). Explaining failures in spoken language comprehension by children with reading disabilities. In D. A. Balota, G. B. Flores d'Arcais, \& K. Rayner (Eds.), Comprehension processes in reading ( $\mathrm{p}$. 539-555). Lawrence Erlbaum Associates, Inc.

50. Bar-Shalom, E. G., Crain, S., \& Shankweiler, D. (1993). A comparison of comprehension and production abilities of good and poor readers. Applied Psycholinguistics, 14(2), 197-227.

51. Bishop, D. V. (1992). The underlying nature of specific language impairment. Journal of child psychology and psychiatry, 33(1), 3-66.

52. Morris, R. D., Stuebing, K. K., Fletcher, J. M., Shaywitz, S. E., Lyon, G. R., Shankweiler, D. P., Katz, L., Francis, D. J., \& Shaywitz, B. A. (1998). Subtypes of reading disability: Variability around a phonological core. Journal of Educational Psychology, 90(3), 347373. https://doi.org/10.1037/0022-0663.90.3.347

53. Mattis, S. (1978). Dyslexia syndromes: A working hypothesis that works. Dyslexia: An appraisal of current knowledge, 43-58.

54. Catts, H. W. (1993). The relationship between speech-language impairments and reading disabilities. Journal of Speech, Language, and Hearing Research, 36(5), 948-958. 
55. Neville, H. J., Coffey, S. A., Holcomb, P. J., \& Tallal, P. (1993). The neurobiology of sensory and language processing in language-impaired children. Journal of Cognitive Neuroscience, 5(2), 235-253.

56. MacArthur, C. A., Graham, S., Haynes, J. B., \& DeLaPaz, S. (1996). Spelling checkers and students with learning disabilities: Performance comparisons and impact on spelling. The Journal of Special Education, 30(1), 35-57.

57. Grigorenko, E. L. (2001). Developmental dyslexia: An update on genes, brains, and environments. The Journal of Child Psychology and Psychiatry and Allied Disciplines, 42(1), 91-125.

58. Pennington, B. F., \& Lefly, D. L. (2001). Early reading development in children at family risk for dyslexia. Child development, 72(3), 816-833.

59. Snowling, M. J., Gallagher, A., \& Frith, U. (2003). Family risk of dyslexia is continuous: Individual differences in the precursors of reading skill. Child development, 74(2), 358-373.

60. Lyytinen, H., Ahonen, T., Eklund, K., Guttorm, T. K., Laakso, M. L., Leinonen, S., \& Richardson, U. (2001). Developmental pathways of children with and without familial risk for dyslexia during the first years of life. Developmental neuropsychology, 20(2), 535-554.
61. Lyytinen, H., Aro, M., Eklund, K., Erskine, J., Guttorm, T., Laakso, M. L., \& Torppa, M. (2004). The development of children at familial risk for dyslexia: Birth to early school age. Annals of dyslexia, 54(2), 184-220.

62. Fenson, L., Dale, P., Reznick, J., Bates, E., Thal, D., Pethick, S., Stiles, J. (1994). Variability in Early Communicative Development. Monographs of the Society for Research in Child Development, 59(5), I-185. doi:10.2307/1166093

63. Baley, R. (1993). U.S. Patent No. 5,223,068. Washington, DC: U.S. Patent and Trademark Office.

64. Reynell, J., \& Huntley, M. (1987). The Reynell Developmental Language Scales.Windsor: NFERNelson.

65. Dun NJ, Karczmar AG. Blockade of ACh potentials by $\alpha$-bungarotoxin in rat superior cervical ganglion cells. Brain research. 1980 Sep 8;196(2):536-40.

66. Tsesmeli, S. N., \& Seymour, P. H. (2006). Derivational morphology and spelling in dyslexia. Reading and Writing,: An Interdisciplinary Journal, 19(6), 587.

67. Bourassa, D. C., \& Treiman, R. (2008). Morphological constancy in spelling: A comparison of children with dyslexia and typically developing children. Dyslexia, 14(3), 155-169. 